\title{
ANALYTICAL MODELS FOR MACHINE TOOL MOTION BEHAVIOR ASSESSMENT BENCH MARK SUBJECTED TO GREAT EARTHQUAKE
}

\author{
PAULO DA SILVA \& IKUO TANABE \\ Nagaoka University of Technology. Dept. of Mechanical Engineering, Nagaoka, Japan.
}

\begin{abstract}
Three large earthquakes hit Japan in the last few years continuously. It affected country's economy and hard to recover specially the manufacturing sector. For avoiding such impacts in the future, lessons were studied and actions were taken. This study therefore was conducted to assess the basic minimum machine tool motion behavior criteria by utilizing the existing seismic data. Particularly, the Japan real earthquake data (The $2004 \mathrm{Ch}$ etsu and the Great Hanshin earthquakes as well as the $2011 \mathrm{~T}$ hoku earthquake) and mathematical models that mimic the movement of machine tools with screw jack mounting during seismic occurrence were considered and developed. For the validity, both mathematical analysis and experimental performances of a previously developed small mock-up structure of a machine tool were conducted. The study concludes that (1) the possible motion behavior of a machine tool was able to be defined and calculated; (2) using the existing real seismic data able to predict the motion behaviour of a machine tool; and (3) it was observed that up-to approximately $60 \%$ accuracy obtained when using the real earthquake data and the developed mathematical models for analysing machine tool motion behavior.
\end{abstract}

Keywords: earthquake-resistance, machine tool motion, risk management.

\section{INTRODUCTION}

In the last few years, Japan was hit by three unforgettable large earthquakes (the 1995 Great Hanshin earthquake [1], the $2004 \mathrm{Ch}$ etsu earthquake [2], and the $2011 \mathrm{~T}$ hoku earthquake and tsunami [3]). It affected country`s economy specially the manufacturing sector. For avoiding the future reoccurrence effects, lessons were taken [4]; actions for disaster recovery and responds improvements were deemed as necessary [5]. Here, comprehensive compilations on machine tool motion behaviour due to earthquake risk researches that cover a wide range of related manufacture recovery ability and machine tool earthquake resilient issues are currently available. The aforementioned disaster was not only resulting in economical loss but also makes hard for the manufacture sector to recover [6] [7]. In regard to this, previous study briefly highlighted the essence of minimising machine tool motion such as overturning, falling or displacing [8]. Machine tool motion behavior particularly on internal structure analysis [9] and its deterioration due to vibration influence during earthquake is discussed [10]. In addition, some leading organizations standardized the machine tool anchoring for resisting earthquake disaster by avoiding moving, rotating or falling [11] [12]. However, it was viewed that although anchoring approach considerably safe for preventing machine tool motion during seismic activity, the manufacture production area could be affected [13]. Meanwhile, the deformation of machine tool due to large earthquake acceleration out of clearance range and its prevention strategies have not been discussed [14]. On the other hand, researches argue that due to the internal stresses, the generated acceleration from earthquakes does not have significant impacts on machine tool accuracy and deformation. The main concern that they asserted is the displacement or crash of machine tools instead [14] [15]. A study on machine tool motion behavior [10] is existing yet very broad discussion and the parallel, 
rotational and falling down motion are not taken into account specifically. This study thus presents basic machine tool performance criteria for earthquake resistance to avoid catastrophic motion during seismic occurrence. Specifically, the machine tool earthquake motion resistance was analysed by utilizing a linear motor lathe machine tool, recorded real Japan earthquake acceleration data [1] [2] [3] and a developed mock-up machine tool structure. The dynamic force in regard to translation and rotational motion of machine tool during earthquake was considered as basis for the proposed analysis concept. To obtain a set of reliable earthquake resistance criteria, the Japan 2004 Ch etsu largest data was used for the mock-up vibration analysis. It was selected due to the highest acceleration vector compare with other two earthquakes. Although, the detail model was presented in our previous paper [17], it did not adequately present the application of the developed model for machine tool motion behavior. Therefore, this work was carried out to validate the models, specifically both parallel and rotational motion scenarios into a real Japan seismic data. It was able to observe that up-to approximately $60 \%$ accuracy obtained from the developed model calculations.

\section{MACHINE TOOL MOTION BEHAVIOR ANALYSIS APPROACH}

Here it dicusses four motion scenarios which are shown in Fig. 1. Particularly, Fig. 1(a) depicts the changes or stress distribution of structure in a fixed-support condition which has explored in a previous study [16]. Meanwhile Fig. 1(b) and (c) show the parallell and rotational movements of machine tool respectively. On the other hand, Fig. 1 (d) reveals the catastrophic crash of machine tool. Here it is important to be asserted that both Fig. 1(b) and (c) were used as relevant aspects for risk assessment criteria and for analysing collisions that may occur between machine tools and it's soroundings. Meanwhile, Fig. 1(d) was used to analyse machine tool behavior in regard to overturn or falling down scenario. The mathematical analytical model for each motion behaviors were developed and presented in the following discussions.

\subsection{Mathematical model for the parallel displacement scenario}

For the parallel movement scenario, when a force $F(=M a(t))$ is applied to the centre of gravity, the acceleration $\alpha(t)$ resultant of earthquake will become higher than the friction force $\pm \mu \mathrm{Mg}$ ( $\mu$ = Coefficient of friction, $M=$ mass of a structure, $\mathrm{g}=$ Gravity acceleration) and the parallel motion of the structure would occur like stick slipping. This concept is shown in Fig. 2. It shows an earthquake oscillation in both north-south directions with an acceleration $a(t)$. It was defined that south direction as positive, and north direction as negative coordinates. The model evaluated a single fluctuation cycle of the parallel motion, while the condition at the end of cycle of the structure was considered in a static condition. Several rectangular partitions were used for a single fluctuation cycle of earthquake acceleration at every $\Delta t$ time step $\left(=\Delta t \times a_{\mathrm{n}}\right)$. It demonstrated that the impulse $\left(M\left(a_{\mathrm{n}}-\mu \mathrm{g}\right) \Delta t\right)$ encounters to the momentum over the structure $\left(M V_{\mathrm{n}}\right)$. Where, $V_{\mathrm{n}}$ required structure speed during stick

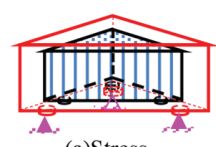

(a)Stress distribution

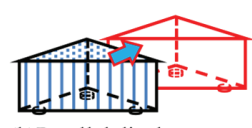

(b)Parallel displacement

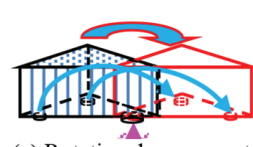

(c) Rotational movement

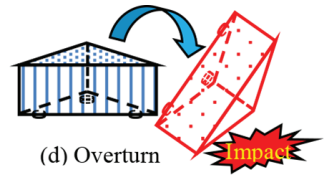

Figure 1: Schematic view of machine tool movement scenarios. 


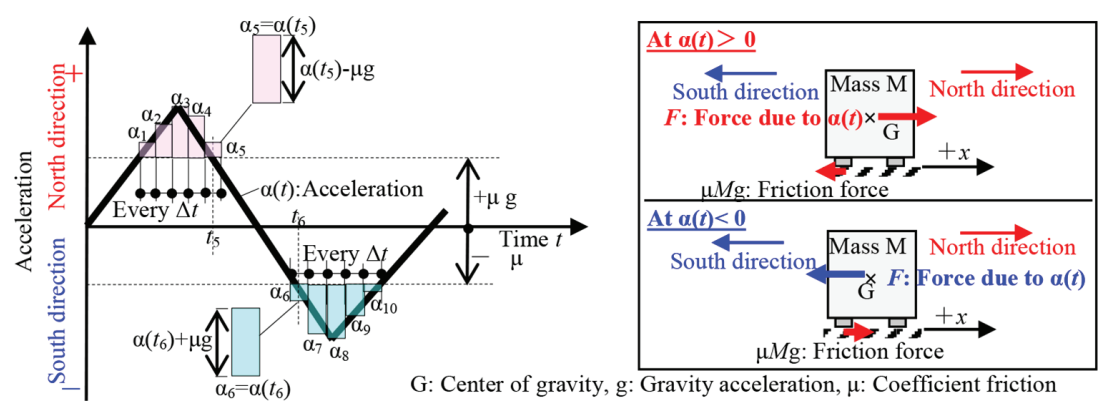

Figure 2: A basic model for the parallel displacement scenario analysis.

slipping motion. The kinetic energy applied in the structure $\left(=1 / 2 M V_{\mathrm{n}}{ }^{2}\right)$ is the work needed to move a $\mathrm{x}$ distance $(\mu \operatorname{Mg} x)$. So the motion scenario can be estimated by summing all the partitions in the equation 1 .

$$
X_{\mathrm{n}}=\sum_{\mathrm{n}=1 \sim 5} \frac{1}{2 \mu \mathrm{g}}\left(\alpha_{\mathrm{n}}-\mu \mathrm{g}\right)^{2} \Delta t^{2}-\sum_{\mathrm{n}=6 \sim 10} \frac{1}{2 \mu \mathrm{g}}\left(\alpha_{\mathrm{n}}+\mu \mathrm{g}\right)^{2} \Delta t^{2}
$$

By using the partitions, which are revealed in Fig. 2, both north $\left(X_{\mathrm{n}}\right)$ and south $\left(X_{\mathrm{s}}\right)$ directions ( $\mathrm{n}$ is the number of partitions) with positive acceleration are calculated with eqn (1). Therefore the overall parallel movement in both directions can be estimated as ' $X_{\mathrm{n}}+X_{\mathrm{s}}$ '. Here it can be said that other parallel displacement like east and west $\left(X_{\text {ew }}\right)$ can also be calculated. However, due to the earthquake fluctuation in up and down motion, the model does not consider the ground shape and ground friction coefficient. By saying that the model was able to present parallel movement assessment concept which rely on ground friction coefficient and enabling the mock-up structure usage, not on the structure mass.

\subsection{Mathematical model for the rotational movement scenario}

In this rotational movement scenario, it considers the composite of both a north-south and east-west acceleration vector as $\alpha_{\mathrm{NEWS}}(t)$ that applied in the structure center of gravity, then producing a resultant force of $F\left(=M a_{\text {NSEW }}(t)\right)$. As indicated in Fig. 3, the rotational coordinate center is denoted $+\theta_{\mathrm{a}}$, and considers clockwise motion for this scenario. It was also defined that the center of rotation was to be a single support which is support $a$ for this scenario. In this scenario, the friction force $\mu M_{\mathrm{s}} \mathrm{g}$ ( $\mu$ : Coefficient of friction, $M_{\mathrm{s}}$ : mass on support $s, g$ : gravity acceleration, where $\mathrm{s}=1,2,3 \ldots$ ) is exhibited by each support of the structure. From Fig. 3(b), it considers a $L_{\mathrm{aG}}$ vector from the center of rotation to the center of gravity of the structure and the distance from the support $a$ to support $s$ is denoted as a vector $L_{\text {as }}$.

In this scenario, it was predicted that when ' $M a_{\mathrm{NSEW}}(t) \times L_{\mathrm{aG}}$ ' greater than the sum of ' $\sum_{\mathrm{s}=1,2, \ldots \text { (number of the supports -1) }} \mu M_{\mathrm{s}} \mathrm{g} L_{\mathrm{as}}$ ' a rotational motion will take place. From Fig. 3(a), the vector accelerations and the total summation of ' $\sum_{\mathrm{s}=1,2, \ldots \text { (number of the supports - 1) }} \mu M_{\mathrm{s}} \mathrm{g} L_{\mathrm{as}}$ ' that represents a scalar was able obtained. The blue circle indicates the rotational motion threshold; meanwhile the green rectangular areas reveal the interval time that structure experienced the rotational motion, its magnitude, and the direction in which the motion occurs during an earthquake.

The impulse at each $\Delta t_{\mathrm{i}}$ time intervals is ' $\left[\left(M \alpha_{\mathrm{NSEW}}(t) \times L_{\mathrm{aG}}\right)-\sum_{\mathrm{s}=1,2, \ldots}\right.$ (number of the supports - 1) $\left.\mu M_{\mathrm{s}} \mathrm{g} L_{\mathrm{as}}\right] \Delta t^{\prime}$ that converges with the angular momentum in the structure $I_{\mathrm{a}} \omega_{\mathrm{a}}(t)\left(I_{\mathrm{a}}:\right.$ moment 


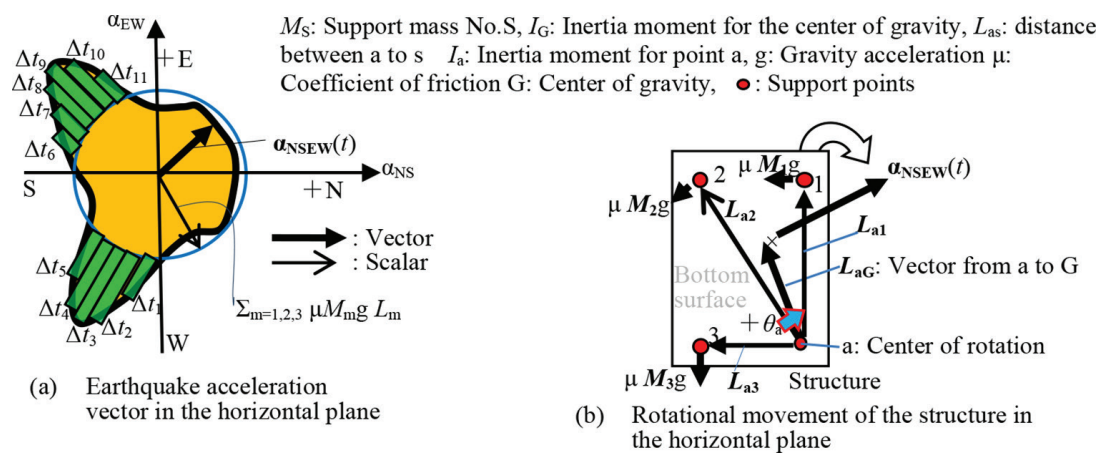

Figure 3: A basic model for the rotational motion scenario analysis.

of inertia over the support point a of the structure, $\omega_{\mathrm{a}}(t)$ : angular velocity over the support point $a$ of the structure at time $t)$. Here it considers the angular kinetic energy acting in the structure $\left(=1 / 2 I_{\mathrm{a}} \omega_{\mathrm{a}}(t)^{2}\right)$ is the work needed for the structure to rotate a $\theta_{\mathrm{x}}$ angle $\left(\mu M \mathrm{~g}\left|L_{\mathrm{aG}}\right|\right.$ $\theta_{\mathrm{x}}$ ) over the support point $a$. The rotational motion is estimated by summing up the total amount of partitions in the eqn (2).

$\theta_{\mathrm{x}}=\sum_{\mathrm{n}=1 \sim 11} \frac{1}{2 \mu \mathrm{g} M I_{\mathrm{a}}}\left[\left(M \alpha_{\mathrm{NSEW}}(t) \times L_{\mathrm{aG}}\right)+\sum_{\mathrm{S}=1,2 ;(\text { number of the supports }-1)} \mu M_{\mathrm{s}} \mathrm{g} \times L_{\mathrm{as}}\right]^{2} \Delta t_{\mathrm{n}}^{2}$

It is important to be noted here that this scenario does not take into account a change in the ground shape and also in the ground friction coefficient because of up-down oscillation. Moreover, the overall earthquake fluctuation time was distributed or divided in time $\Delta t$ partitions. Meanwhile the rotational motion of the structure at each $\Delta t$ can be calculated by eqn (2). So, the aforementioned model is suitable for the rotational motion analysis.

\subsection{Mathematical model for the overturn scenario}

In this scenario, the mathematical model for structure falling down or crash is depicted in Fig. 4. Specifically, this scenario represents the event in which the earthquake oscillation produced motion is contrary to the greater friction forces, ground support protuberance and crash. Here, the vector $a_{\text {NEWS }}(t)$ shows the acceleration in north-south and east-west directions. The resultant of force $F\left(=M \alpha_{\text {NEWS }}(t)\right)$ applied in the center of the structure gravity. During earthquake, it is able to observe that the acceleration in up-down motion can be represented as ' $\mathrm{g}-\alpha_{\mathrm{ud}}(t)$ ' $\left(a_{\mathbf{u d}}(t)\right.$ : earthquake acceleration at time $t$ in the up-down direction, g: gravity acceleration). From Fig. 4, it can be seen that the point $a$ to the center of gravity denoted with ' $L_{\mathrm{aGs}}$ ', and ' $M \alpha_{\mathrm{NSEW}}(t) \times L_{\mathrm{aG}}$ ' is considered as the moment in clockwise direction to the support point $a$.

Here, it can be noted that the gravity acceleration contradicts the crash motion and the moment can be denoted as $\mathrm{M}\left(\mathrm{g}-a_{\mathrm{ud}}(t)\right) \times \mathrm{L}_{\mathrm{aG}}$. Therefore, the minimum condition for a structure not overturn is represented in the eqn (3).

$$
\text { No overturn } \Rightarrow\left(\mathrm{g}-a_{\mathrm{ud}}(t)\right) \times L_{\mathrm{aG}}>a_{\mathrm{NSEW}}(t) \times L_{\mathrm{aG}}
$$




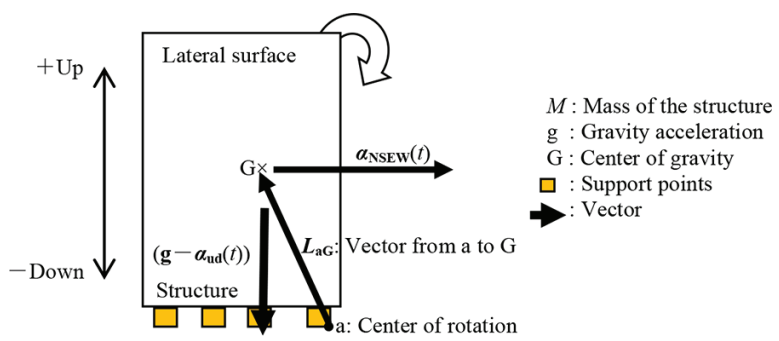

Figure 4: A basic model used for the overturn scenario analysis.

From this, it can be stated that when the earthquake acceleration in up-down direction can directly influence the gravity acceleration, then it is possible for structure to overturn. It was also able to observe that when even only light or medium earthquake acceleration in up-down direction, the overturn of a structure can possibly occur. Also it is noticed that when the distance of center of gravity increases in height, the chance of crash will high, as right hand side of eqn (3) value will increase. Again, from this model, it was possible to present the coherent model to calculate the overturn scenario. Here, it only considered the support $a$ for the calculation, however other supports can also be estimated by using the same approach.

\section{THE EXPERIMENTAL SETUP FOR MACHINE TOOL EARTHQUAKE MOTION BEHAVIOR ANALYSIS}

Based on the proposed model which presented in the chapter 2, the arrangements for experiments were conducted in the machining center of Nagaoka University of Technology (NUT). A linear motor lathe with carriage and head stock specifications which are shown in the Table 1 was used for the experiment. In addition, the developed mock-up structure to mimic a machine tool vibration behaviour during an earthquake activity was also deployed for the experiment. It consisted of several bolts and nuts as well as plates (Fig. 5). Meanwhile, Fig. 6 shows the developed mock-up structure is placed on the steel plate with dimension of 412

Table 1: Specifications of liner motor lathe machine.

\begin{tabular}{|c|c|c|}
\hline \multirow{6}{*}{ 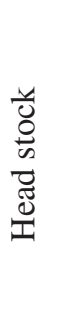 } & Max. spindle speed & $10000 \mathrm{~min}^{-1}$ \\
\hline & Stroke on $\mathrm{Z}$ direction & $200 \mathrm{~mm}$ \\
\hline & Max. acceleration on $\mathrm{Z}$ direction & $12.1(1.23 \mathrm{G}) \mathrm{m} / \mathrm{s}^{2}$ \\
\hline & Max. speed on $\mathrm{Z}$ direction & $90 \mathrm{~m} / \mathrm{min}$ \\
\hline & Max. load on $\mathrm{Z}$ direction & $1674 \mathrm{~N}$ \\
\hline & Positioning accuracy of $\mathrm{Z}$ & $0.3 \mu \mathrm{m}$ \\
\hline \multirow{6}{*}{. } & Stroke on $\mathrm{X}$ direction & $195 \mathrm{~mm}$ \\
\hline & Max. acceleration on $\mathrm{X}$ direction & $19.6(2.0 \mathrm{G}) \mathrm{m} / \mathrm{s}^{2}$ \\
\hline & Max. speed on X direction & $110 \mathrm{~m} / \mathrm{min}$ \\
\hline & Max. load on X direction & $1674 \mathrm{~N}$ \\
\hline & Positioning accuracy of $\mathrm{X}$ & $0.5 \mu \mathrm{m}$ \\
\hline & Table size & $410 \times 80 \times 434 \mathrm{~mm}$ \\
\hline
\end{tabular}




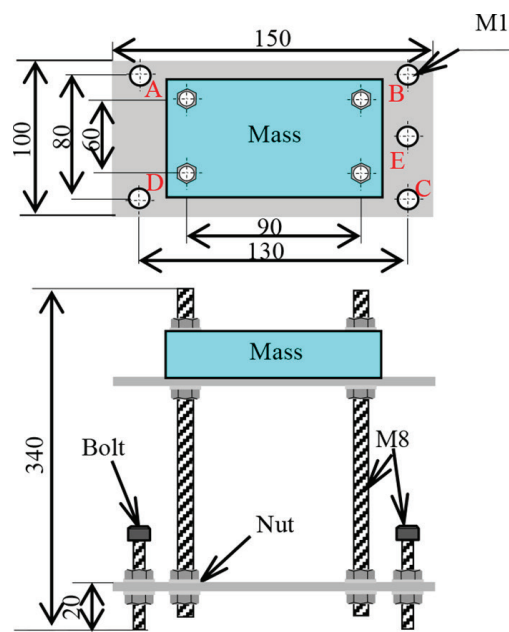

(a) Drawing of the structure 4supports: A-B-C-D

3supports: A-D-E

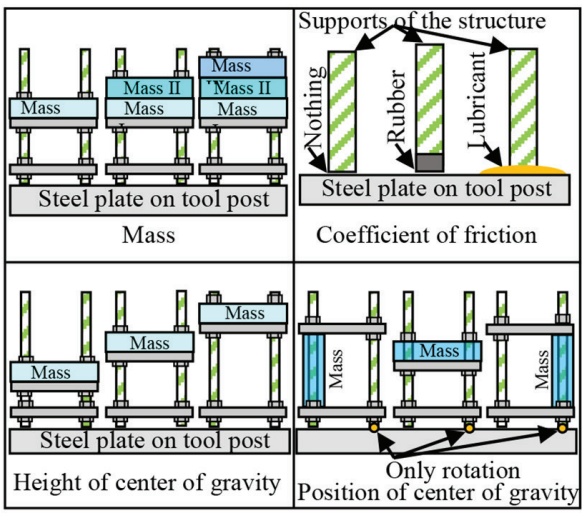

(b) Available parameters

Figure 5: Schematic views of the developed machine tool mock-up.

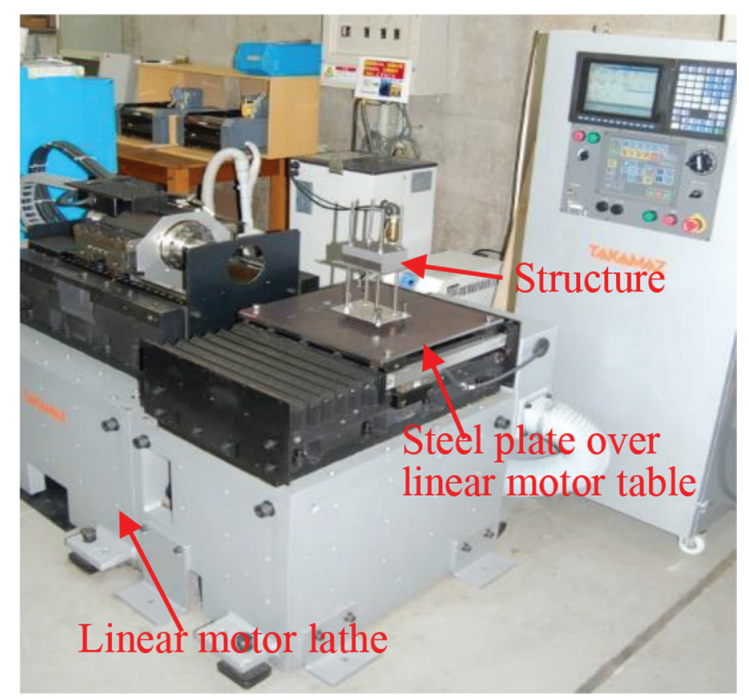

Figure 6: Mock-earthquake experimental setup.

$\mathrm{mm} \times 427 \mathrm{~mm} \times 9 \mathrm{~mm}$ that was mounted on the machine tool table during the experimentation for all three motion scenarios.

The linear lather table was able to move at $2 \mathrm{~g}$ ( $\mathrm{g}$ : acceleration of gravity) in the X direction which is in-line with earthquake accelerations. The used machine tool supports were including screw jacks, leveling pads and jacks. Through the screw jacks mimic supporting systems and other foundation supporting systems that present in the production area, the developed mock-up structure was used to simulate the anchoring system.

For the hardest earthquake situation, a metal-metal interface foundation was chosen to analyze the structure motion during seismic activity. It must be highlighted that a metalconcrete interface shown a $1 / 10$ of the support stiffness of a metal-metal interface in previous 


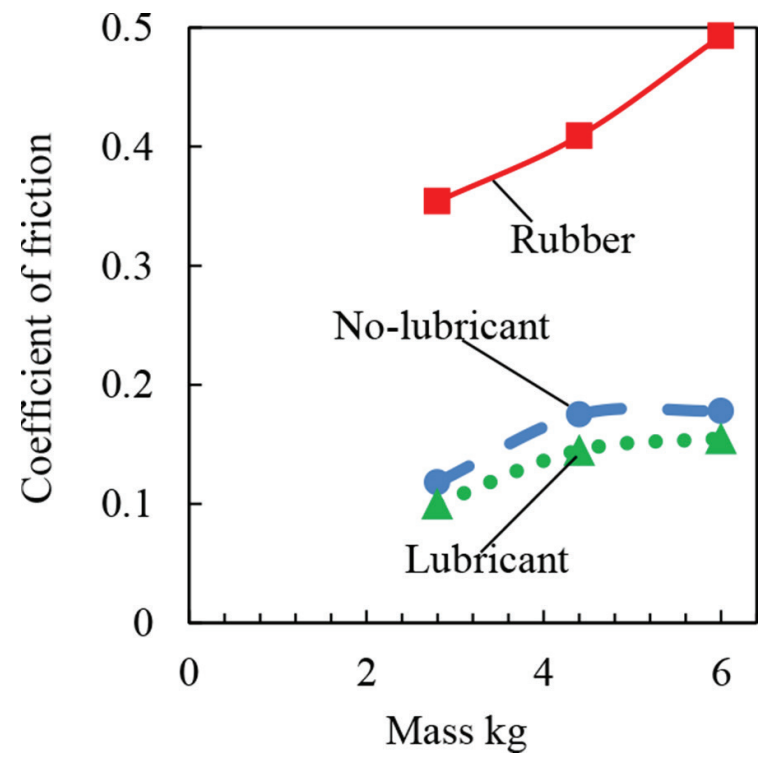

Figure 7: Coefficient friction between the structure and the plate.

studies [13]. On the other hand, Fig. 7 exhibits the friction coefficient of various foundation situations. Meanwhile, Fig. 8 reveals the acceleration in X direction of plate. Both friction coefficient and the plate acceleration were measured and obtained prior to the actual experimentation of mock-up structure motion analysis for the proposed models. By using a very fine wire, the structure gravity center over the plate was pulled at $300 \mathrm{~mm} / \mathrm{s}$. Then, it used a pull tension gauge for measuring the pulling load. Meanwhile, dynamic friction coefficient was estimated by using the pulling load. The relationship of time and table position data that recorded from high speed camera measurements was used to calculate the accelerations.

\section{EXPERIMENTAL AND ANALYTICAL RESULTS}

\subsection{The experimental and analytical results of parallel displacement scenario}

The experimental parameters and conditions that used for the analysis are shown in the Table 2. The mathematical analysis of this parallel movement scenario of mock-up structure was done by using Eq. 1. The parameters were; masses of the structure, including 2.8, 4.4 and $6.0 \mathrm{~kg}$; this was deemed as important due to a non-linear relationship between the coefficient of friction and mass of the structure. Meanwhile the considered friction conditions between the plate and the structure were without lubricant, with lubricant, lubricant oil with ISO VG5 and rubber seat. Finally, Fig. 8 exhibits, the acceleration and deceleration of the plate after one cycle motion. Here, the parallel displacement of the developed structure was measured with a tape measurement device. The mathematical model for parallel displacement scenario calculation results is revealed in Fig. 9. From both mathematical model analysis and experimental evaluation results, the parallel displacement analysis approach was reliable for such situation, as both results are approximate close. Similarly, as indicated in the mathematical model (1), the experimental results reveal that the relationship between the mass of the structure and the parallel movement could be negligible. It was considered that there is a strong correlation between the mass of structure and coefficient friction; as it was noted that when 


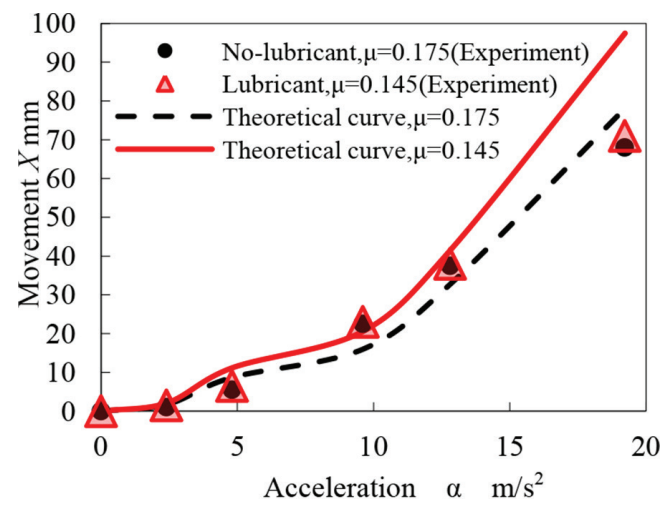

(b) Mass $m=4.4 \mathrm{~kg}$

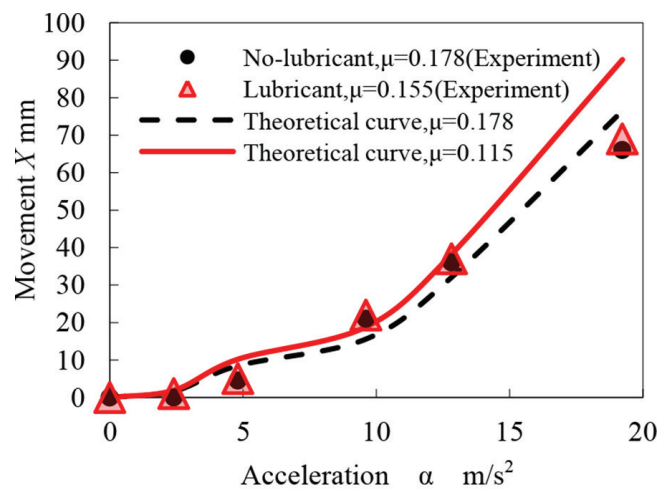

(c) Mass $m=6.0 \mathrm{~kg}$

Figure 9: Experimental and analytical results of the parallel movement scenario.

the mass of the structure was changed, the coefficient of friction was also changed. The evaluation results indicate that the parallel movement reveals non-linear behavior and the model could be applied to machine tools of multiple dimensions. Moreover, Fig. 9 depicts that the displacement was remarkably similar between the lubricant and no-lubricant cases. This indicates that the lubrication in the production area has no significant role in this motion scenario.

However, in contrary when a rubber pad was used, the developed structure overturned in every case, and the parallel movement was not measured which could be considered in the support selection process after a risk assessment. It was concluded from this scenario evaluation that the structure parallel motion was influenced by both coefficient of friction and the acceleration of the earthquake. It noted that if the coefficient friction becomes large, the parallel displacement becomes small and there is a high possibility of structure to overturn. On the other hand, when applied the mass of the structure $(2.8 \mathrm{~kg}$ which is small) the contact between the structure and the ground was significantly unstable. Here, the displacement figures between the experiment and the theoretical analysis became significantly large. 
4.2 The experimental and analytical results of the rotational movement scenario

The evaluation of this scenario was using eqn (2) and the conditions revealed in the Table 3. The used structure mass was $4.4 \mathrm{~kg}$, the distances from the rotational center to the center of the structure on the plate were $30 \mathrm{~mm}, 75 \mathrm{~mm}$ and $120 \mathrm{~mm}$. The contact conditions between the structure and the plate were no-lubricant and with lubricant oil with ISO VG5. Finally, the accelerations of plate after moving one cycle shown in Fig. 8 and Table 3 include $2.4 \mathrm{~m} / \mathrm{s}^{2}$, $4.8 \mathrm{~m} / \mathrm{s}^{2}, 9.6 \mathrm{~m} / \mathrm{s}^{2}, 12.8 \mathrm{~m} / \mathrm{s}^{2}$ and $19.2 \mathrm{~m} / \mathrm{s}^{2}$. Meanwhile, two supporting points including free rotation and non-fixed (Table 3) were considered. Here, a protractor was deployed for the structure rotational motion measurements.

Figure 10 reveals the rotational movement scenario results for three different distances ( $30 \mathrm{~mm}, 75 \mathrm{~mm}$ and $12 \mathrm{~mm}$ ) from the center of gravity. Based on this result, it was thought that the proposed mathematical model was appropriate for the rotational movement analysis, as both analytical and experimental results are approximate. From the study it noted that the contact coefficient of friction, the reaction force of supports, position taken at the center of gravity and earthquake acceleration were factors that directly influenced the rotational movement of

Table 3: Experimental conditions for rotational movement scenario.

\begin{tabular}{|c|c|c|}
\hline \multicolumn{2}{|l|}{ Items } & Conditions \\
\hline \multicolumn{2}{|l|}{ Acceleration $\mathrm{m} / \mathrm{s}^{2}$} & $2.4,4.8,9.6,12.8,19.2$ \\
\hline \multicolumn{2}{|l|}{ Acceleration curve } & $\rightarrow$ See Fig. 10 \\
\hline \multirow{2}{*}{\multicolumn{2}{|c|}{ Available interfaces between the structure and the plate }} & None \\
\hline & & ISO VG5 \\
\hline \multicolumn{2}{|l|}{ Mass m Kg } & 4.4 \\
\hline \multicolumn{2}{|c|}{ Distance from center of gravity D mm } & $30,75,120$ \\
\hline \multirow[t]{3}{*}{ Position } & \multicolumn{2}{|c|}{ Acceleration direction } \\
\hline & $\overline{\mathrm{O}+\mathrm{D}} \quad$ O St & $\begin{array}{l}\text { lpport points } \\
\text { otation free) }\end{array}$ \\
\hline & ${ }^{\mathrm{OSu}}$ & $\begin{array}{l}\text { pport points } \\
\text { on-fixed) }\end{array}$ \\
\hline
\end{tabular}

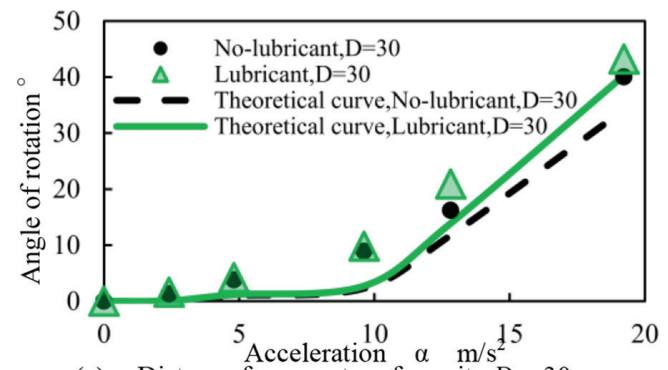

(a) Distance from center of gravity $D=30 \mathrm{~mm}$ 


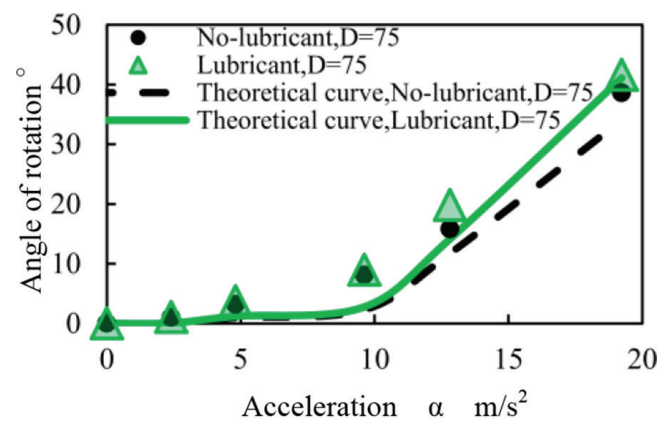

(b) Distance from center of gravity $D=75 \mathrm{~mm}$

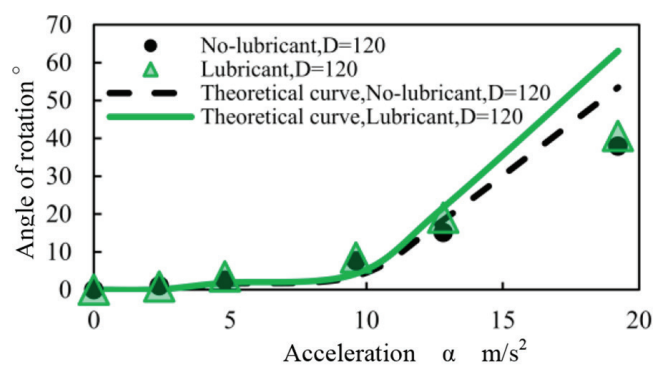

(c) Distance from center of gravity $D=120 \mathrm{~mm}$

Figure 10: Experimental and analytical results of the rotational movement scenario.

machine tool. Therefore, considering the proposed analytical model will help to obtain an appropriate anchoring system for avoiding rotational motion during an earthquake activity.

Here, it was able to observe that the rotational movement of structure will increase if the distance from the center of gravity becomes large. This can lead to structure unstable and resulted in overturn. Therefore, it is important for factories and workshops in most earthquake vulnerable locations to arrange its machine tools with proper countermeasures, using these models, for avoiding both rotational and parallel movements before having catastrophic crash.

\subsection{The experimental and analytical results of the overturn scenario}

The mathematical analysis model (eqn (3)) for the overturn scenario was conducted by using condition shown in the Table 4 . They are the structure mass of $4.4 \mathrm{~kg}$, the contact conditions between plate and the developed mock-up model were without lubricant, with lubricant oil of ISO VG5 and rubber seat. From the experiment, it was noted that when only rubber pad was used, the developed mock-up structure overturned. To analyze the overturn motion, both Models I and II (Table 4) and respected conditions were considered during the experiment. Meanwhile, the plate one cycle of acceleration and deceleration that considered is shown in Fig. 8 and Table 4. On the other hand, Fig. 11 exhibits the mathematical analysis and experimental results of overturn structure scenario. The coherent results of both evaluations indicate that this analytical model can be appropriate for overturn analysis. Additionally, it was noted that both gravity restoration force and the moment of the earthquake acceleration influenced 
Table 4: Experimental conditions for the overturn scenario.

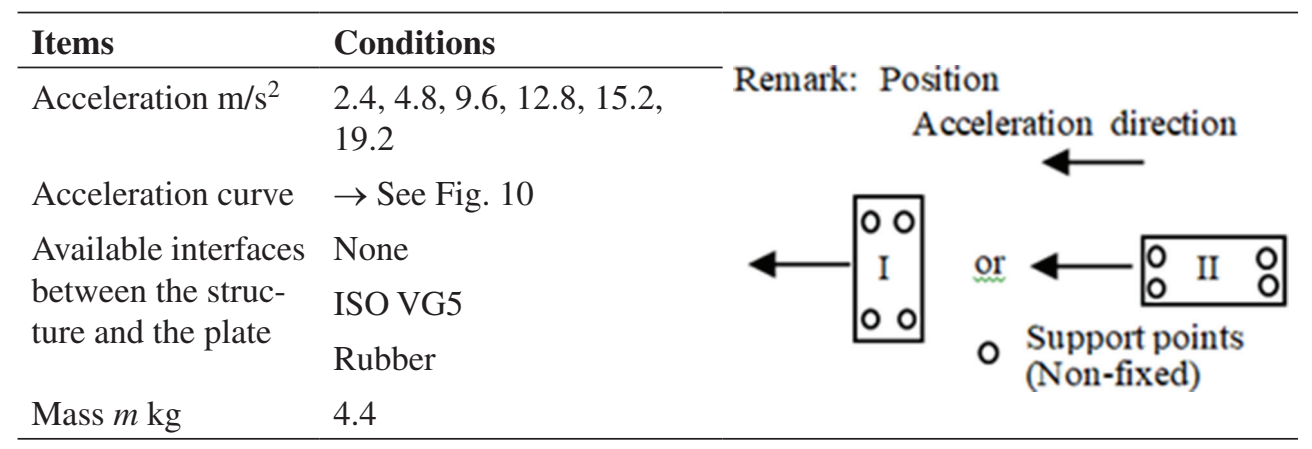

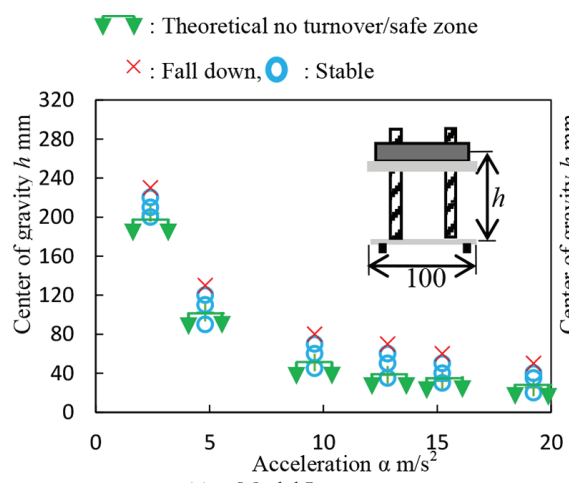

(a) Model I

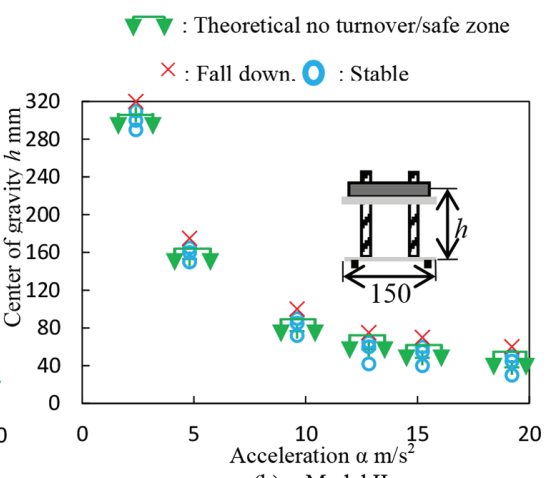

(b) Model II

Figure 11: Experimental and analytical results of overturn scenario.

the overturn structure scenario. Consequently, it can be stated that the machine tool overturn scenario can be evaluated by deploying past real earthquake data (section 2) and the analytical model (eqn (3)). It however the up-down direction of earthquake acceleration and the mass and height of the structure influence the gravitation restoring force over the structure. Therefore, in the risk assessment stage, the aforementioned considerations should be taken into account for a safe earthquake-resilient anchoring selection.

Finally, the height of center of gravity and the relationship between position, support points and the center of gravity are need to be taken into account when designing anchoring system, as it is essential aspect for overturn motion analyze purpose.

\section{MACHINE TOOL MOTION BEHAVIOR CALCULATION BY CONSIDERING THE REAL SEISMIC DATA}

From an internal survery which was conducted at machining center of Nagaoka University Technology that used the real Japan 2004 Chuetsu large earthquake [2], [15] data, it exhibits that out of 84 machine tools, 1 overturned, 2 experienced significant displacement before caused great catastrophic impacts among all the machine tools. Meanwhile, 81 machine tools experienced parallel movement. As it stated in the previous study [14], there was no impacts on machine tool accuracy that recorded from these machines due to earthquake accelerations. 
Specifically, the recorded data of a CNC machining center on October 23rd at the NUT (see Fig. 12 and Table 5) machining warehouse, as results of Japan 2004 Chuetsu earthquake disaster, is presented in Table 6.

The displacement data of machine tools as results of large earthquake accelerations were obtained from the aforementioned measurement. With the same approach, both eqns (1) and (2) were used for the machine's rotational and parallel movement calculations. The CNC machining center mass was $6500 \mathrm{~kg}$ which occupied an area of $2166 \mathrm{~mm} \times 2685 \mathrm{~mm}$.

For the sake of analysis, it was assumed that the structure of machine tool was to be a rectangular block with uniformly density distribution and height $h$, and it was supported by four base corners. The $L$ was denoted as the distance between the center of gravity and the support point of rotational gravity. Meanwhile, $I_{\mathrm{a}}$ as moment of inertia, was calculated as ' $I_{\mathrm{a}}=M\left(a^{2}+b^{2}\right) / 12+M L^{2}$ ' by using the eqn (2). The calculation was done by using the

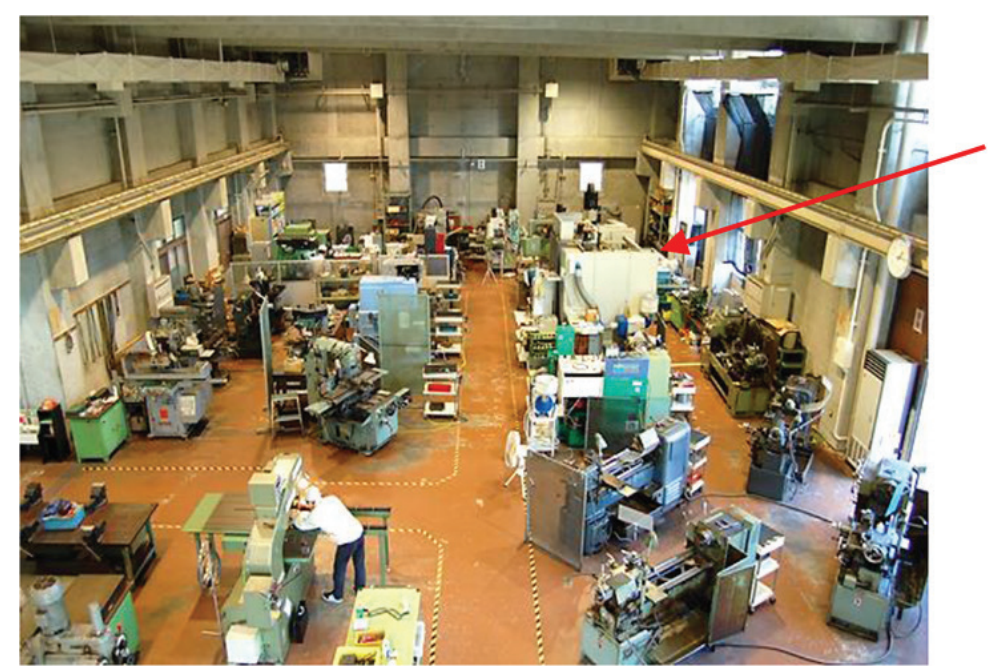

$\mathrm{CNC}$ machining center

Figure 12: Photograph of the surveyed machine shop.

Table 5: Specifications of the surveyed machine shop.

Surface area: $26 \times 14 \mathrm{~m}$

\section{Dimensions}

Total machine tools (Machine tool occupied area rate)

Average factory users

East wall dimensions (Area occupied by windows)

South wall dimensions (Shutter dimensions)

West wall dimensions (Entrance dimensions)

North wall dimensions (Amount of ventilation units)
Height : 7 m

$52(54 \%)$

20/day

$28 \mathrm{~m} \times 7 \mathrm{~m}(23 \%)$

$14 \mathrm{~m} \times 7 \mathrm{~m}$

$(3.6 \mathrm{~m} \times 3.6 \mathrm{~m})$

$28 \mathrm{~m} \times 7 \mathrm{~m}$

$(2.4 \mathrm{~m} \times 2.5 \mathrm{~m})$

$14 \mathrm{~m} \times 7 \mathrm{~m}(2)$ 
Table 6: The real and calculated proposed method of parallel and rotational motion of a CNC machining center under the 2004 Chuetsu

large earthquake data.

\section{Parallel movement relative to gravity center Rotational \\ movement}

\begin{tabular}{lccc} 
Machine tool & NS direction & EW direction & (+:Clockwise) \\
\hline $\begin{array}{l}\text { Real behavior after } \\
\text { the 2004 Chuetsu } \\
\text { earthquake }\end{array}$ & S $83.2 \mathrm{~mm}$ & E $132.8 \mathrm{~mm}$ & $+5^{\circ}$ \\
$\begin{array}{l}\text { Calculation using Eq. } 1 \\
\text { and Eq. 2. }\end{array}$ & S $47.3 \mathrm{~mm}$ & E $66.4 \mathrm{~mm}$ & $+2.9^{\circ}$ \\
\begin{tabular}{l} 
Calculation accuracy \\
\hline
\end{tabular} & $56.9 \%$ & $50.0 \%$ & $5.0 \%$ \\
\hline
\end{tabular}

Calculation accuracy $[\%]=$ Difference between calculated and real values

$\div$ real values $\times 100$

previously recorded [11] acceleration curves. Both Table 6 and Fig. 13 present the calculation results from eqns (1) and (2). Here, the foundation coefficient friction $\mu$ which used for the calculation was 0.132 . From the estimation outcome, it able to observe a calculation accuracy between $50 \%$ to $60 \%$. However the distance from the actual earthquake point and the experimentatal site (NUT) as well as position and ground conditions were contribute slightly to the results.

As most of the machine tools have very high stiffness; stress distribution or deformation that gained during earthquake are in significant. However, as maintaining machine tools' accuracy is important; therefore, post-earthquake maintenance for machine tool is essential after it experienced both a parallel displacement and a rotational movement in factories. On the other hand, when a catastrophic overturn or tumbling occurs, machine tools may be seriously affected due to large earthquake gravity acceleration. The friction between the machine tools and the floor in factory is believed to be the main influence of this during the large earthquake occurrence. These need to be aware and its behavior can generally be analysed by using the proposed model in this research.

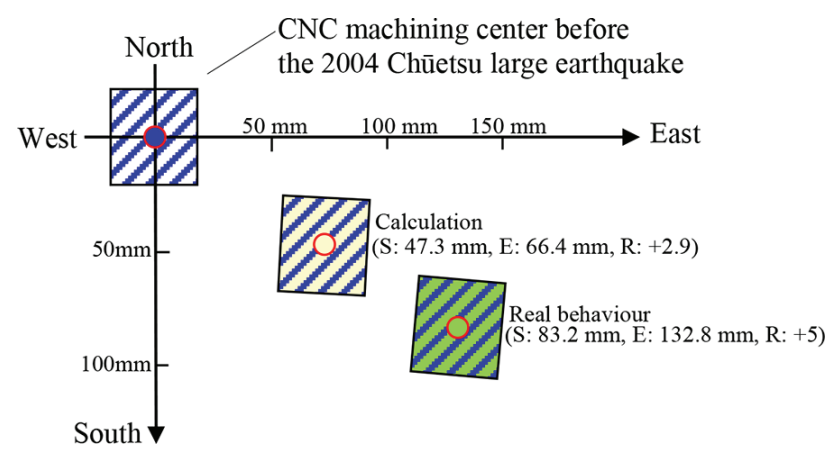

Figure 13: The real and calculated proposed method of parallel and rotational motion of a CNC machining center under the $2004 \mathrm{Ch}$ etsu large earthquake data. 


\section{CONCLUSION}

The overall results from study are briefly summarized:

1. The parallel movement of a structure is influenced by coefficient friction and earthquake accelerations. When coefficient friction become large then the displacement becomes small, the possibility of having structure overturn will high. Meanwhile, the rotational movement of structure will increase when the distance from the center of gravity large. Then the structure will become instable and leads to crash.

2. Both mathematical analysis and experimental evaluation results were approximate. The developed models are deemed as appropriate approach for machine tool risk assessment criteria.

3. The developed analytical models for all scenarios (parallel, rotational and overturn motions) for machine tool behavior assessment was effectively performed as it was able to observe up-to approximately $60 \%$ accuracy when using real earthquake data for both rotational and parallel movement. Therefore, these models are considered suitable for investigating related earthquake issue and reliable for seismic risk assessment criteria that provides a better anti-seismic anchoring model selection.

\section{REFERENCES}

[1] Morita, T., Ten years past after the Great Hanshin-Awaji earthquake. Modern Firefighting Co. Ltd., pp. 7-255. 2005. (In Japanese)

[2] Nagaoka city, The Chūetsu Earthquake (Effect Regarding Risk Management of Self -Governing Bodies). Gyousei Co. Ltd., pp. 1-224, 2005. (In Japanese)

[3] Satake, K. \& Hori, M., Sciences of Tōhoku Earthquake, University of Tokyo Press, pp. 1-243, 2011. (In Japanese)

[4] Kourakata, I., Report of the damage and the repair condition on the manufacturing industry at the Chūetsu-oki earthquake in Kashiwazaki. Annual Report of Research Institute Hazards \& Disaster Recovery, 2, pp. 109-113, 2008. (In Japanese)

[5] Moriwaki, T., Risk management of the manufacturing industry at the Great Hanshin-Awaji earthquake. Trend-eye '95, Kobe city Ind. foundation, pp. 1-10, 1995. (In Japanese)

[6] Minami, T., Economy effects of the Tōhoku earthquake in Japan. Norinchukin Research Institute Co. Ltd., Financial Market, 2011/04, pp. 1-3, 2011.

[7] Brunsdon, D., Critical infrastructure and earthquakes: understanding the essential elements of disaster management. Australian Earthquake Engineering Society, Paper No. 28, pp. 1-7, 2002.

[8] Friedman, L. \& Porter, K., Use of logic tree analysis for earthquake emergency planning in critical facilities. In Proceedings of the Second Conference on Earthquake Hazards in the Eastern San Francisco Bay Area, eds. G. Borchardt, and others, California Department of Conservation, Division of Mines and Geology Special Publication 113, pp. 469-473, 1992.

[9] Koenigsberger, F., Machine Tool Structures, Pergamon Press Ltd., pp. 451-456, 1970.

[10] Goyal, D. \& Pabla, B.S., Condition based maintenance of machine tools-A review. CIRP Journal of Manufacturing Science and Technology, 10, pp. 24-35, August 2015.

[11] SLAC National Accelerator Laboratory, Machine Tool Requirements. SLAC National Accelerator Laboratory, pp. 1-7, 2013.

[12] Federal Emergency Management Agency, Installing Seismic Restraints For Mechanical Equipment. Federal Emergency Management Agency, pp. 1-147, 2002.

[13] Kono, D. \& Inagaki, T., Stiffness model of machine tool supports using contact stiffness. Precision Engineering, 37(3), pp. 650-657, July 2013. 
[14] Japan Society of Mechanical Engineers, Report of Great Hanshin-Awaji earthquake (For Mechanical Engineering). 2013. Japan Society of Mechanical Engineers, pp. 339-408, 1998. (In Japanese)

[15] Japan Society of Mechanical Engineers, Report of Tōhoku earthquake (For Mechanical Engineering). Japan Society of Mechanical Engineers, pp. 403-432, 2013. (In Japanese)

[16] Japan Meteorological Agency, Observed data of major earthquakes. Japan Meteorological Agency, 2017. (In Japanese): http://data.jma.go.jp/svd/eqev/data/kyoshin/jishin/index.html?sess=6e1b37b3613bd087e7ce042e42f4670b

[17] da silva, P. \& Tanabe, I., Risk assessment criteria for machine tools subjected to large earthquake hazards -A proposal. WIT Transactions on the Built Environment, Structures under Shock and Impact XV, ISSN 1743-3509, 180, pp. 195-207, 2018. 